\title{
FERMENTACIÓN "FEED BATCH" PRODUCCIÓN DE DEXTRANASACARASA
}

Juan Heraldo Viloche Bazán ${ }^{1}$

\author{
R E S U M E N
}

La enzima Dextranasacarasa fue producida por fermentación del Leuconostoc Mesentoreoides NRRL B512-F por un sistema "feed baich" de 3 litros de capacacidad con un caudal de aereación de $0,5 \mathrm{I} / \mathrm{min}$, una velocidad de agitación de 200 RPM y un control de pH. El pH fue mantenido en 6.7 \pm 0.2 por la adición de una solución combinada de sacarosay NaOH a iravés de la acción de una bomba operada por el controlador.

A B S TRACT

The Dextranasaccharase enzyme was produced by fermentation of Leuconostoc Mesentoreoides NRRL B512-F through 3 its. capacity batch system with 0,5 1/min flowing aeration, 200 RPM agitation speed and $p H$ control. $p H$ was kept at $6,7(0,2$ by the addition combined solution of saccharose and $\mathrm{NaOH}$ through pump action operated by a controller.

\section{PROPIEDADES}

La Dextranasacarasa (1-6- - -glucosiltransferasa) es una enzima extracelular, producida por muchos microorganismos del tipo: Leuconostoc, Streptococcus y Lactobacillus, que tienen la propiedad de sintetizar la dextrana a partir de la sacarosa. Las propiedades, mecanismos de reacción, métodos de producción y purificación de esta enzima, están relativamente caracterizados, principalmente la enzima producida del Leuconostoc Mesenteroides NRRL B512-F, que produce una dextrana con dos tipos de uniones glucosidicas: $\quad(1,6)$ y $\quad(1,3)$.

Durante muchos años se pensó que la sacarosa era el único substrato conocido para la inducción de la producción de la dextranasacarasa, porque azúcares como, glucosa, fructosa, manosa, lactosa, etc., sólo promueven el crecimiento vegetativo de la bacteria, pero sin producción de la enzima. Otros

1. Mgr. en Ingeniería de Alimentos estudios demuestran que muchos compuestos conteniendo una unión -D-glucosídica con energía similar a la de la sacarosa, sirven como substrato para la producción de la dextranasacarasa.

La Dextranasacarasa cataliza la sintesis de dextrana a partir de la sacarosa en un amplio rango de temperatura (de 0 a $40^{\circ} \mathrm{C}$ ). En la reacción no intervienen compuestos fosforilados y la energia para la formación de las unidades glucosídicas, es proporcionada por la hidrólisis de la sacarosa.

La enzima bruta y liofilizada retiene la actividad por varios años, cuando es almacenada a temperaturas menores de $5^{\circ} \mathrm{C}$. En solución, varios factores influencian en la estabilidad de la enzima, siendo la temperatura y el $\mathrm{pH}$ dos de los parámetros fundamentales. La presencia de dextrana, polímeros neutros como polietilenglicol (PEG), metilcelulosa y detergentes neutros aumentan significativamente la estabilidad de la enzima. En cambio, la presencia de $\mathrm{Cu}^{+2}, \mathrm{Zn}^{+2}, \mathrm{Hg}^{+2}$ y EDTA, inhiben la actividad enzimática. 
La energía de activación aún no está bien determinada, encontrándose en la literatura valores de 5 a $11 \mathrm{Kcal} / \mathrm{mol}$. La cinética es descrita por el modelo de inhibición por el substrato alcanzando una velocidad máxima a $200 \mathrm{mM}$ de substrato.

La enzima dextranasacarasa puede ser producida por dos sistemas: batch y feed batch, siendo el feed batch el sistema que mejor rendimiento produce. La adición de sacarosa puede ser realizada de dos formas: adición de sacarosa combinada con el sistema controlador de $\mathrm{pH}$ y adición independiente del pH (alimentación separada de solución de sacarosa en forma continua con una velocidad de 18 g/l.h y alimentación de solución de $\mathrm{NaOH}$ de acuerdo al controlador de $\mathrm{pH}$ ).

\section{MATERIALES Y MÉTODOS}

\subsection{REACTIVOS}

El microorganismo usado en las fermentaciones "feed batch", para la produción de la enzima, fue el Leuconostoc Mesenteroides NRRL B512-F, almacenado a $-20^{\circ} \mathrm{C}$ en solución de glicerol a $10 \%$.

\subsection{METODOLOGIA}

\subsubsection{Medio patrón}

Los componente del medio de patrón fueron diluidos en agua destilada y ajustado el $\mathrm{pH}$ a 6,7 con $\mathrm{HCl}$. El fosfato fue diluido separadamente

\begin{tabular}{|lc|}
\hline \multicolumn{2}{|c|}{ MEDIO PATRÓN } \\
\hline COMPONENTES & $\mathrm{G} / \mathrm{L}$ \\
Sacarosa & 40 \\
Extracto de levadura & 20 \\
Sulfato de Magnesio & 0,2 \\
Cloruro de sodio & 0,01 \\
sulfato de magnesio & 0,01 \\
Cloruro de calcio & 0,01 \\
\hline \multicolumn{2}{|c|}{ T A M P Ó N } \\
\hline Fosfato de potasio dibásico \\
\hline
\end{tabular}

y el $\mathrm{pH}$ tambien fue ajustado a 6.7 . Ambas soluciones fueron esterilizadas separadamente a $121^{\circ} \mathrm{C}$ por 15 min y luego mezcladas en frio.

\subsubsection{Inóculo}

Se preparó en un Erlenmeyer de $250 \mathrm{ml}$, conteniendo 100 de medio patrón estéril y con un tubo de cultura conteniendo el Leuconostoc Mesenteroides NRRL B512-F, a la temperatura de $27^{\circ} \mathrm{C}$, con una agitación de 200 RPM durante 12 horas.

\subsubsection{Alimentación}

Se utiliza el sistema de alimentación combinada, porque la demanda de sacarosa está asociada al crecimiento y el control de $\mathrm{pH}$ es más adecuado. Se prepara $400 \mathrm{ml}$ de sacarosa de 120 a $250 \mathrm{~g} / \mathrm{l}, 100 \mathrm{ml}$ de $\mathrm{NaOH} 5 \mathrm{~N}$ y se esterilizan separadamente a $121^{\circ} \mathrm{C}$ por 15 minutos. Después se mezclan (en frio) para obtener una solución final de 80 a $200 \mathrm{~g} / \mathrm{l}$ de sacarosa y $\mathrm{NaOH} 1 \mathrm{~N}$.

\subsubsection{Fermentación}

Fue utilizado un fermentador de la New Brunswick de 3 litros de capacidad, que contenía $900 \mathrm{ml}$ de medio patrón estéril. Después de adicionar el inóculo, se incuba a la temperatura de 27 a $29^{\circ} \mathrm{C}$, con un caudal de aire de $0,5 \mathrm{l}$ min, una agitación de 200 RPM y con un control de $\mathrm{pH}$ en $6.7 \pm 0,2$, mediante la adición de una alimentación de la solución combinada, preparada de acuerdo con el item anterior, a través de la acción de una bomba operada por el control automático de $\mathrm{pH}$ del fermentador. Al final de la fermentación se regula el pH a 5,2 con $\mathrm{HCl}$ y se centrifuga a 10000 RPM a $4^{\circ} \mathrm{C}$ por 15 minutos con la finalidad de eliminar las células.

\subsubsection{Extracción de la Dextranasacarasa}

Después de eliminar las células, el caldo es colocado en un baño de hielo y sometido a una ultrafiltración hasta conseguir una concentración aproximada de enzima, 10 veces la concentración inicial. Al concentrado, con agitación y a $4^{\circ} \mathrm{C}$, se adiciona lentamente una solución de polietilenglicol 1500 al 50\% (PEG 1500 ), hasta que la solución se torne turbia y luego se centrifuga a $10000 \mathrm{RPM}$ a $4^{\circ} \mathrm{C}$ y 15 minutos. La fase inferior rica en enzima dextranasacarasa se disuelve en una solución tampón de acetato de sodio $200 \mathrm{mM} \quad(\mathrm{pH} 5.2$ conteniendo $0,5 \mathrm{~g} / \mathrm{l}$ de cloruro de calcio) y se almacena en frascos $\mathrm{a}-15^{\circ} \mathrm{C}$.

\subsection{MÉTODOS ANALITICOS}

\subsubsection{Crecimiento celular}

Se determina la concentración celular en el 
medio de cultura por el método espectrofotométrico, por la lectura de la absorbancia a $650 \mathrm{~nm}$ (utilizando agua destilada para calibrar el espectrofotómetro).

\subsubsection{Determinación de azúcares reductores (Método de DNS)}

\section{a) Preparación del reactivo DNS}

Se disuelve 10,16 gramos de ácido 3,5-dinitrosalicílico (DNS) en $1416 \mathrm{ml}$ de agua destilada. Se adiciona $7,6 \mathrm{ml}$ de fenol (fundido a $50^{\circ} \mathrm{C}$ ) y $8,32 \mathrm{~g}$ de metabisulfito de sodio y se guarda este reactivo en un frasco proteguido de la luz. En forma paralela se prepara una solución de tartaratro doble de sodio y potasio $11,25 \mathrm{~g} / \mathrm{l}$ y se guarda en otro frasco.

\section{b) Curva patrón}

Se prepara soluciones de glucosa, con concentraciones entre 0,1 a $1 \mathrm{~g} / /$ de azúcares reductores. Se toma $1 \mathrm{ml}$ de estas concentraciones en tubos de ensayo, $1 \mathrm{ml}$ de reactivo DNS y se coloca en un "baño maria" en ebullición por 5 minutos. Se enfria instantáneamente por la inmersión de los tubos en baño de hielo fundente y enseguida se añade $16 \mathrm{ml}$ de solución de tartaratro doble de sodio y potasio para estabilizar el color. Después de homogeneizar los tubos, se lee la absorbancia a $540 \mathrm{~nm}$ en un espectrofotómetro.

\section{c) Azúcares Reductores Totales}

Para determinar azúcares reductores totales, primero debe hacerse la inversión de la sacarosa por hidrólisis ácida. Se mezcla $1 \mathrm{ml}$ de la muestra con $1 \mathrm{ml}$ de $\mathrm{HCl} 2 \mathrm{~N}$ y se mantiene durante 5 minutos en "baño maria" en ebullición. Despues de enfriar se añade $1 \mathrm{ml}$ de $\mathrm{NaOH} 2 \mathrm{~N}$ y luego se procede de la misma forma descrita en la curva patrón.

\subsubsection{Actividad enzimática}

Se determina la actividad de la enzima midiendo la velocidad inicial de producción de fructosa. Se coloca entre 0,1 a $1 \mathrm{ml}$ de solución enzimática, $0,5 \mathrm{ml}$ de tampón acetato $200 \mathrm{mM}$ ( $\mathrm{pH} 5,2$ conteniendo $2,5 \mathrm{~g} / \mathrm{l}$ de $\mathrm{CaCl}_{2}$ ) y agua hasta completar $10 \mathrm{ml}$ en un reactor enchaquetado de vidrio. Cuando la solución, agitada magnéticamente, llega a $30^{\circ} \mathrm{C}$ se agrega $2 \mathrm{ml}$ de solución sacarosa $600 \mathrm{~g} / \mathrm{l}$ y se va retirando muestras cada 3 minutos, determinando fructosa por el método de azúcares reductores. La actividad enzimática puede ser determinada por la ecuación:

$$
\mathrm{ACT}=\text {.B.d.114 (UDS } / \mathrm{ml})
$$

donde:

: coeficiente de la curva ABS vs tiempo

$B$ : coeficiente de la curva patrón de AR

d : volumen de dilución final del reactor.

\section{RESULTADOS Y DISCUSIÓN DE LOS RESULTADOS}

Las fermentaciones "feed batch", con Leuconostoc Mesenteroides NRRL B512-F, fueron realizadas usando las condiciones dadas en materiales y métodos. Una muestra de los resultados, es presentada en la Tabla $N^{\circ} 1$ y en las Figuras Nros. $1,2,3$ y 4 , demostrando que la producción de la enzima dextranasacarasa está asociada al crecimiento celular del Leuconostoc mesenteroides y cesa en la fase estacionaria. En la mayoria de las fermentaciones se procede al corte de la alimentación y al control del $\mathrm{pH}$, después de 7 horas de fermentación, en el final de la fase exponencial, con la finalidad de favorecer la producción de la enzima, así como la disminución de la concentración residual de sacarosa.

TABLA N ${ }^{\circ}$ 1: Rendimiento del proceso de extracción de la Dextranasacarasa

\begin{tabular}{|c|c|c|c|c|c|c|c|c|}
\hline $\mathrm{N}^{\mathrm{a}}$ & $\begin{array}{c}\mathrm{ACT} \\
\mathrm{UDS} / \mathrm{ml}\end{array}$ & $\begin{array}{c}\mathrm{ART} \\
\mathrm{g} / \mathrm{l}\end{array}$ & $\begin{array}{c}\mathrm{Vi} \\
\mathrm{ml}\end{array}$ & $\begin{array}{c}\mathrm{Vp} \\
\mathrm{ml}\end{array}$ & $\begin{array}{c}\mathrm{ACT} \\
\text { UDS/ml }\end{array}$ & $\begin{array}{c}\mathrm{Vf} \\
\mathrm{ml}\end{array}$ & $\begin{array}{c}\mathrm{ACT} \\
\text { UDS } / \mathrm{ml}\end{array}$ & $\begin{array}{c}\mathrm{R} \\
\%\end{array}$ \\
\hline 1 & 56,45 & 2,74 & 2300 & 230 & 309 & 100 & 590.1 & 0,45 \\
$1^{*}$ & 31,89 & 2,74 & 2300 & 230 & 309 & 100 & 590.1 & 0,80 \\
2 & 63,90 & 7,00 & 2500 & 250 & 593 & 100 & 1285 & 0,80 \\
3 & 71,90 & 16,13 & 2800 & 284 & 491 & 100 & 1280 & 0,64 \\
4 & 106,18 & 6,54 & 2700 & 261 & 897 & 100 & 2060 & 0,72 \\
5 & 66 & 1,24 & 2450 & 220 & 598 & 100 & 1210 & 0,75 \\
\hline
\end{tabular}

(*) Actividad después de 6 horas de fermentación.

En la Fig. $N^{\circ} 4$, podemos verificar que la actividad llega a $106 \mathrm{UDS} / \mathrm{ml}$ y $6,54 \mathrm{~g} / \mathrm{l}$ de azúcares reductores totales, en contraste con la Fig. $\mathrm{N}^{\circ} 1$, donde dicha actividad alcanza $56 \mathrm{UDS} / \mathrm{ml}$ a las 5 horas de fermentación, cayendo a $32 \mathrm{UDS} / \mathrm{ml}$ y $2,74 \mathrm{~g} / \mathrm{l}$ de azúcares reductores totales, después de casi 6 horas de fermentación. La disminución de la actividad de la enzima, en el final de las fermentaciones, es tipica de esta enzima, debido a su baja estabilidad en las 
condiciones de fermentación empleadas de temperatura $\left(27 \mathrm{a} 29^{\circ} \mathrm{C}\right)$ y $\mathrm{pH}$ de 6.7

En la Fig. $N^{\circ} 3$ se observa que la cantidad de azúcares reductores es de 16.13 , lo que significa que habia mucho substrato en el medio de fermentación, por lo que el caldo fermentado tiene alta viscosidad al producirse dextrana de alto peso molecular en forma paralela, que no permite realizar un buen proceso de ultrafiltración, teniendo que perderse enzima.

Para la obtención de la enzima con máxima

FIGURA N ${ }^{\circ}$ 1: Fermentación "feed batch" del Leuconostoc Mesenteroides NRRL B512-F, con una alimentación de $80 \mathrm{~g} / \mathrm{l}$ de sacarosa y una temperatura de $28^{\circ} \mathrm{C}$.

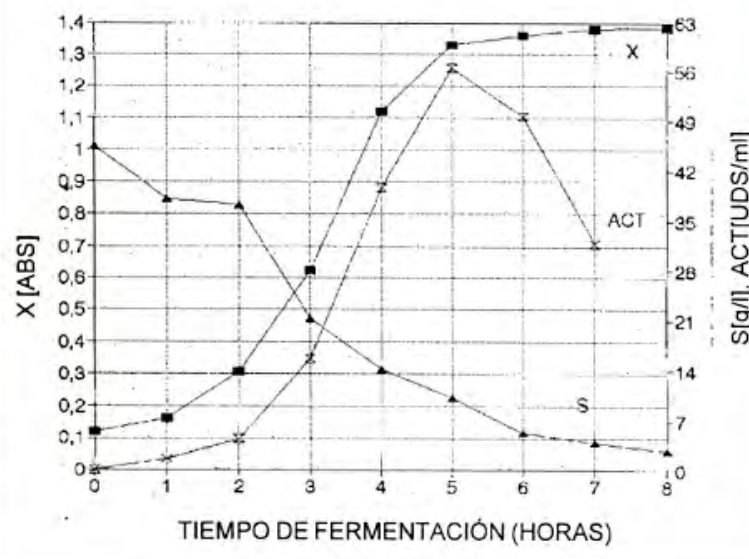

FIGURA N²: Fermentación "feed batch" del Leuconostoc Mesenteroides NRRL B512-F, con una alimentación de $160 \mathrm{~g} / \mathrm{l}$ de sacarosa y una temperatura de $28^{\circ} \mathrm{C}$.

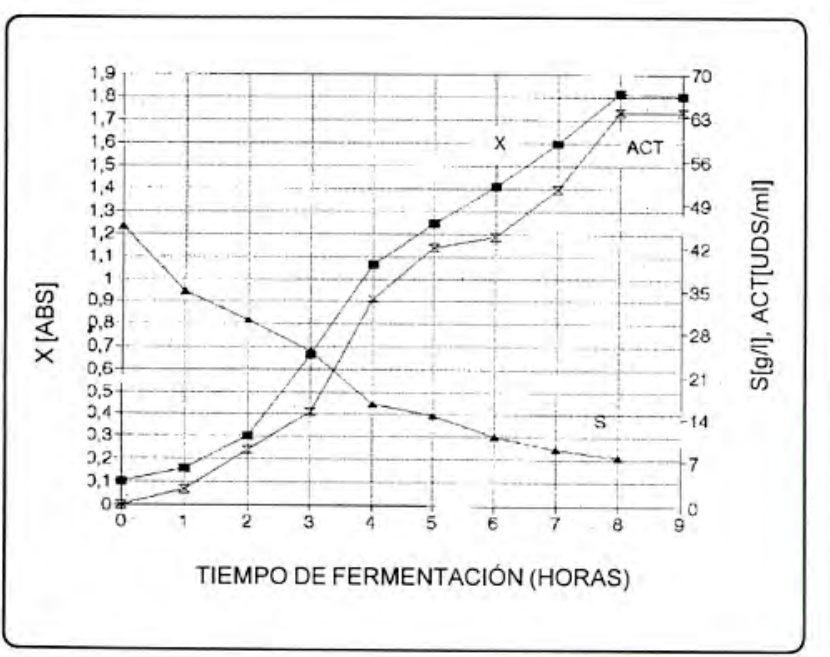

actividad y cantidades minimas de azúcares reductores totales en el final de la fermentación, de acuerdo con la Tabla $\mathrm{N}^{\circ} 1$, la Fig. $\mathrm{N}^{\circ} 4$, fue el experimento que presentó mejores condiciones para la producción de la enzima dextranasacarasa por fermentación en "feed batch" (sacarosa de $160 \mathrm{~g} / \mathrm{l}$, $\mathrm{NaOH} 1 \mathrm{~N}$ y una temperatura de $27^{\circ} \mathrm{C}$ ) con mayor actividad enzimática (106 UDS/ml) y menores cantidades de azúcares reductores $(6,54 \mathrm{~g} / \mathrm{l})$. En vista de estos resultados, se adoptó estas condiciones para la mayor producción de la enzima dextranasacarasa.

FIGURA N ${ }^{\circ}$ 3: Fermentación "feed batch" del Leuconostoc Mesenteroides NRRL B512-F, con una alimentación de $160 \mathrm{~g} / \mathrm{l}$ de sacarosa y una temperatura de $29^{\circ} \mathrm{C}$.

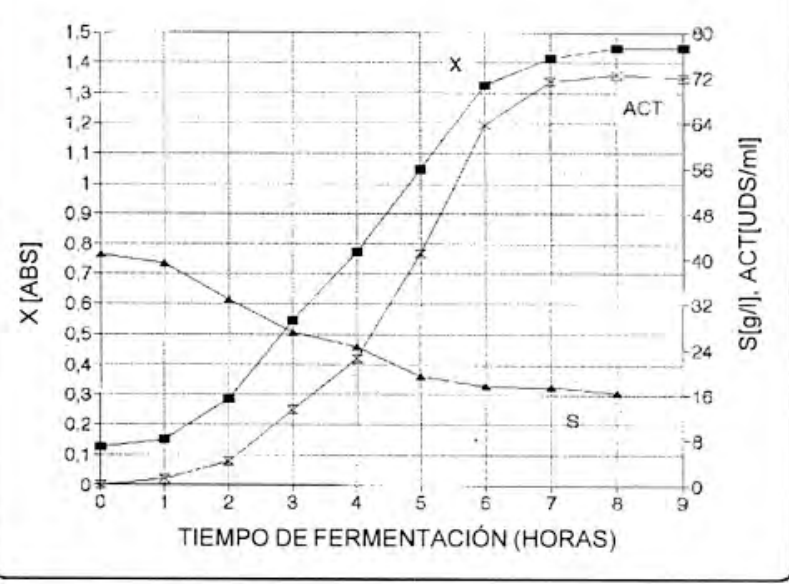

FIGURA N ${ }^{\circ}$ 4: Fermentación "feed batch" del Leuconostoc Mesenteroides NRRL B512-F, con una alimentación de $160 \mathrm{~g} / \mathrm{l}$ de sacarosa y una temperatura de $27^{\circ} \mathrm{C}$.

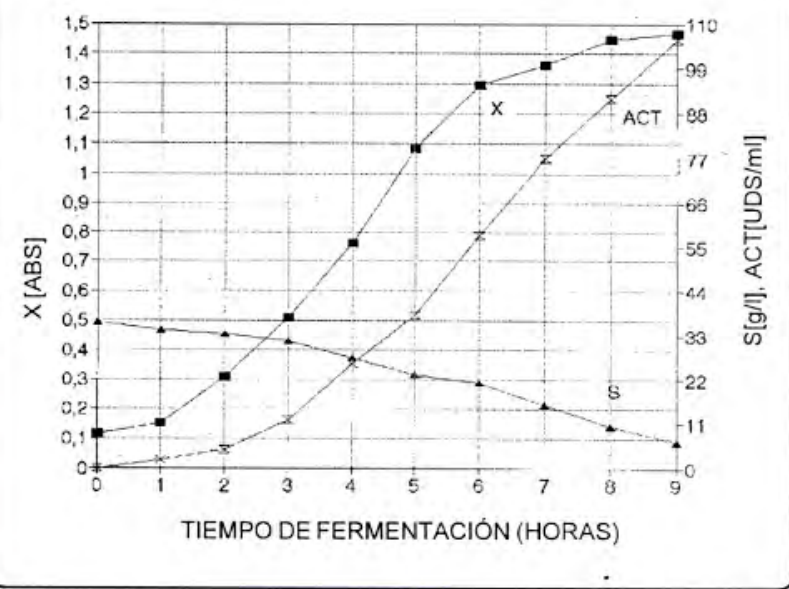




\section{BIBLIOGRAFÍA}

ALSOP, L. Industrial productions o dextran. Progress. Ind. Microbiology. 18: 1-44, 1983.

BARKER, T.P. The Producction of the enzyme dextransucrase using nonaerated fermentations techniques. Biotechnol. Bioeng. 37 703-707, 1991.

BINDER, T.P. \& ROBYT, J.F. P-nitrophenyl $\propto$-d-glucopyranoside a new substrate for glucansucrases. Carbohydr. Res. 124: 287-299, 1983.
HEHRE, H.J. Studies of the enzimatic syntesis of dextran fron sucrose. J.Biol. chem. 163: 221-223, 1946.

VILOCHE, J.H. Estudio de producción enzimática de Dextrana Clínica, Campinas - Sao Paulo, 1993. Tesis de MaestriaFacultad de Ingenieria de Alimentos de la Universidad de Campinas - Brazil.

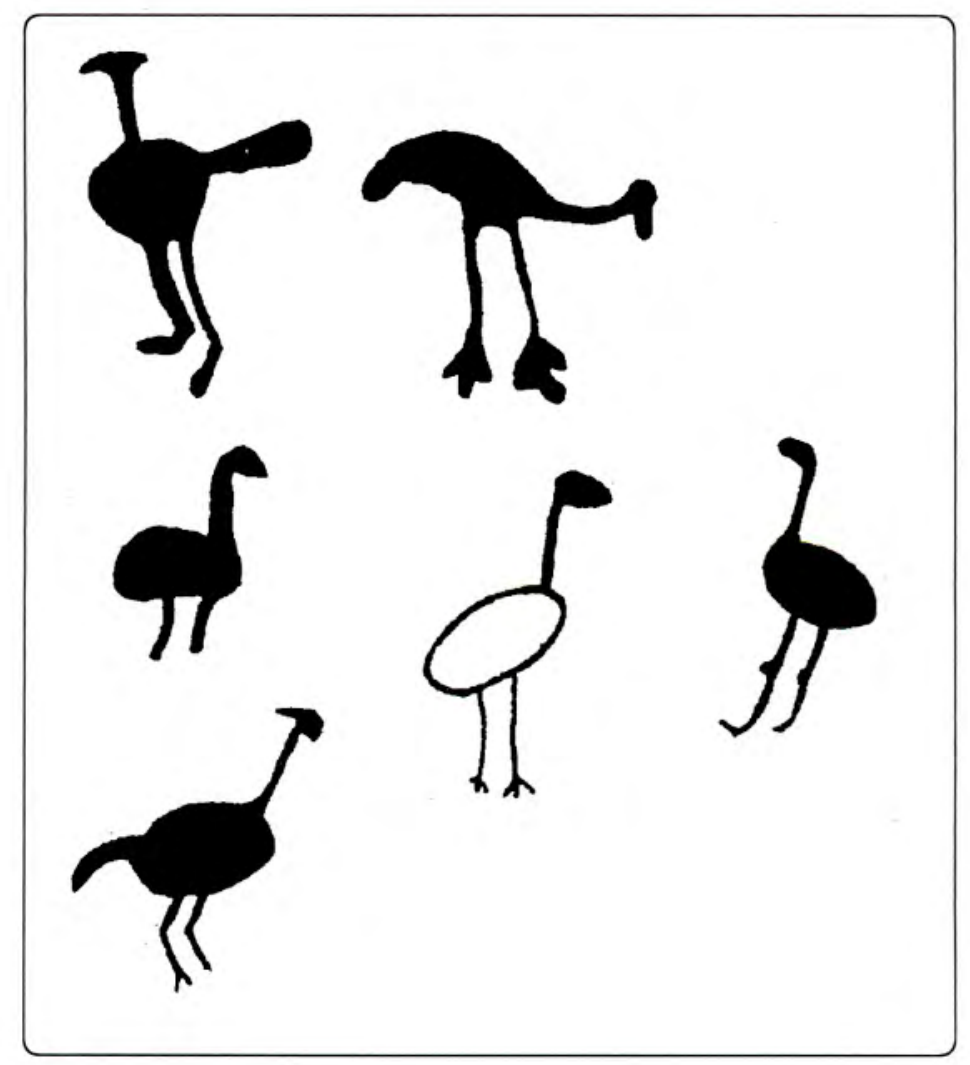

